\title{
Involvement of polyphosphate kinase in virulence and stress tolerance of uropathogenic Proteus mirabilis
}

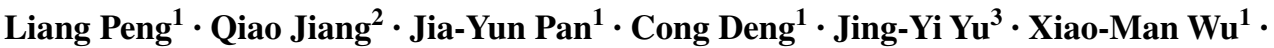 \\ Sheng-He Huang ${ }^{3,4} \cdot$ Xiao-Yan Deng ${ }^{1}$
}

Received: 8 December 2014 / Accepted: 15 July 2015 / Published online: 2 August 2015

(C) The Author(s) 2015. This article is published with open access at Springerlink.com

\begin{abstract}
Proteus mirabilis ( $P$. mirabilis), a gramnegative enteric bacterium, frequently causes urinary tract infections. Many virulence factors of uropathogenic $P$. mirabilis have been identified, including urease, flagella, hemolysin and fimbriae. However, the functions of polyphosphate kinase (PPK), which are related to the pathogenicity of many bacteria, remain entirely unknown in $P$. mirabilis. In this study, a $p p k$ gene encoding the PPK insertional mutant in $P$. mirabilis strain HI4320 was constructed, and its biological functions were examined. The results of survival studies demonstrated that the $p p k$ mutant was deficient in resistance to oxidative, hyperosmotic and heat stress. The swarming and biofilm formation abilities of $P$. mirabilis were also attenuated after the ppk interruption. In vitro and in vivo experiments suggested that $p p k$ was required for $P$. mirabilis to invade the bladder. The negative phenotypes of the ppk mutant could be restored by ppk gene complementation. Furthermore,
\end{abstract}

Sheng-He Huang

shhuang@hsc.usc.edu

$\triangle$ Xiao-Yan Deng dxyzgy@163.com

1 Department of Clinical Laboratory, The Second Affiliated Hospital of Guangzhou Medical University, Guangzhou 510260, China

2 Intensive Care Unit, Guangdong 999 Brain Hospital, Guangzhou 510510, China

3 Department of Microbiology, School of Public Health and Tropical Medicine, Southern Medical University, Guangzhou 510515, China

4 Saban Research Institute, Childrens Hospital Los Angeles, Los Angeles, CA 90027, USA two-dimensional gel electrophoresis and liquid chromatography-mass spectrometry were used to analyze the proteomes of the wild-type strain and the ppk mutant. Compared with the wild-type strain, seven proteins including TonB-dependent receptor, universal stress protein G, major mannose-resistant/Proteus-like fimbrial protein (MR/P fimbriae), heat shock protein, flagellar capping protein, putative membrane protein and multidrug efflux protein were down-regulated, and four proteins including exported peptidase, repressor protein for FtsI, FKBP-type peptidyl-prolyl cis-trans isomerase and phosphotransferase were up-regulated in the $p p k$ mutant. As a whole, these results indicate that PPK is an important regulator and plays a crucial role in stress tolerance and virulence in uropathogenic $P$. mirabilis.

Keywords Proteus mirabilis . Urinary tract infection · Polyphosphate kinase $\cdot$ Virulence

\section{Introduction}

Proteus mirabilis ( $P$. mirabilis) is an important pathogen that causes urinary tract infections (UTIs), especially in patients with indwelling urinary catheters [1]. A recent investigation of clinic UTIs caused by gram-negative bacilli found that $P$. mirabilis-induced UTI was third in infection rates after Escherichia coli and Klebsiella pneumoniae [2]. P. mirabilis colonization and invasion of the uroepithelium are two crucial steps in the pathogenesis processes of UTI. Some virulence factors related to these processes have been identified. Mannose-resistant Proteus-like (MR/P) fimbria, as an adhesin, is important for bacterial adhesion to the uroepithelium. The secreted hemolytic 
Table 1 Primers used for the construction of the $p p k$ mutant and $p p k$ complementation strain

\begin{tabular}{ll}
\hline Primer name & Sequence $\left(5^{\prime}-3^{\prime}\right)$ \\
\hline ppk-IBS & AAAAAAGCTTATAATTATCCTTAAGAGCCTGAGCCGTGCGCCCAGATAGGGTG \\
ppk-EBS1d & CAGATTGTACAAATGTGGTGATAACAGATAAGTCTGAGCCGCTAACTTACCTTTCTTTGT \\
ppk-EBS2 & TGAACGCAAGTTTCTAATTCGATTGCTCTTCGATAGAGGAAAGTGTCT \\
ppk-outF & CAAATATCCCGGTCTGCATACACAT \\
ppk-outR & CAATACACCTTCACGTAATGCACCA \\
EBS universal & CGAAATTAGAAACTTGCGTTCAGTAAAC \\
Intron3end & CAGAGCCGTATACTCCGAGA \\
pGMF & ATAAGTACTTTGAGACAATTTACCGAACAAC \\
pGMR & ATAAGTACTAGAAATGCCTCGACTTC \\
pkF & ATAGATATCATGTCCCAAGAACGACTCTATATTGATAAAG \\
pkR & AGAGGATCCTTACGCTCGTGATCCTGGTTGTTC \\
\hline
\end{tabular}

toxin HpmA contributes to host cell invasion and cytotoxicity [3]. Prior to the successful colonization of the urinary tract, pathogens need to overcome several challenges, including urine flow, antibacterial molecules, $\mathrm{pH}$ and osmotic pressure [4]. Recent research has suggested that the bacterial RNA chaperone Hfq plays a critical role in P. mirabilis adaptation to environmental stress and urinary tract colonization [5]. Flagella-mediated motility and RsbA-mediated fatty acid regulation are both involved in the swarming differentiation and migration, which are characteristics of $P$. mirabilis and related to UTIs caused by $P$. mirabilis.

Polyphosphate kinase (PPK), encoded by the ppk gene, is a major enzyme involved in the synthesis of inorganic polyphosphate (poly P) from ATP. Some studies have indicated that PPK plays an important role in the stress resistance and virulence of several bacteria species. The meningitis $E$. coli $\mathrm{K} 1$ strain with a $p p k$ knockout was deficient in responses to stresses and translocation across the blood-brain barrier [6]. Vibrio cholera ppk mutants were defective in motility and cell surface attachment [7]. Pseudomonas aeruginosa exhibited aberrant quorum sensing and biofilm formation after ppk deletion [8]. Inactivation of ppk in Shigella and Salmonella spp. led to loss of the capacities to resist environmental stress and to invade epithelial cells [9].

However, the function of $p p k$ in $P$. mirabilis remains entirely unknown. In this study, we constructed a $p p k$ mutant strain and investigated the role of $p p k$ in UTIs caused by $P$. mirabilis using both in vitro and in vivo models. In addition, two-dimensional gel electrophoresis and liquid chromatography-mass spectrometry (LC-MS) were employed to analyze the molecular regulation mechanism of ppk in P. mirabilis.

\section{Materials and methods}

\section{Bacterial strains, plasmids and growth conditions}

Proteus mirabilis HI4320 (clinically isolated strain from a patient with UTI, $\operatorname{Tet}^{\mathrm{r}}$ ) was kindly provided by Prof. Harry L. T. Mobley. E. coli TOP10 cells were used as the host for plasmid construction. All strains, including the wild-type strain, the mutant, and the ppk-complemented strain, were cultured at $37{ }^{\circ} \mathrm{C}$ in Luria-Bertani (LB) broth (10 g/L of tryptone, $5 \mathrm{~g} / \mathrm{L}$ of yeast extract and $10 \mathrm{~g} / \mathrm{L}$ of $\mathrm{NaCl})$ and non-swarming agar $(10 \mathrm{~g} / \mathrm{L}$ of tryptone, $5 \mathrm{~g} / \mathrm{L}$ of yeast extract, $5 \mathrm{~mL} / \mathrm{L}$ of glycerol, $0.4 \mathrm{~g} / \mathrm{L}$ of $\mathrm{NaCl}$ and $20 \mathrm{~g} / \mathrm{L}$ of agar). Antibiotic supplementation with ampicillin $(100 \mu \mathrm{g} / \mathrm{mL})$, chloramphenicol $(20 \mu \mathrm{g} / \mathrm{mL})$ or kanamycin $(25 \mu \mathrm{g} / \mathrm{mL})$ was provided as necessary. The plasmids pACD4 K and pAR1219, used for ppk gene mutant construction, were purchased from Sigma-Aldrich. The rabbit polyclonal antibody against PPK protein was constructed in our laboratory.

\section{Construction of the isogenic insertional mutant}

The mutant was constructed using the TargeTron system (Sigma-Aldrich, USA), according to the manufacturer's instructions and as described as by Harry L. T. Mobley, et al. [10]. Briefly, a reprogrammed group II intron (containing a kanamycin resistance gene) was specifically inserted into the site of 201/202a in ppk via mutagenic PCR using the primers ppk-IBS, ppk-EBS2, ppk-EBS1d, and EBS universal (Table 1). The retargeted intron was ligated into plasmid pACD4 K-C (containing a chloramphenicol resistance gene) to create plasmid pACD4 k-ppk and was transformed into $E$. coli top 10 cells by electroporation. Then, the correct recombinant plasmid was introduced 
into P. mirabilis HI4320, which had been previously transformed with a T7 helper plasmid pAR1219 (containing an ampicillin resistance gene). IPTG $(1 \mathrm{mmol} / \mathrm{L})$ was used to induce the intron from pACD4 k-ppk to jump into the ppk gene in the P. mirabilis chromosome (chloramphenicol/ampicillin double-resistant). Successful intron insertion was detected by kanamycin selection. The insertional mutant was confirmed with PCR using the primers ppkoutF and ppk-outR (Table 1). The correct insertion position was sequenced using the primers EBS universal and Intron3end (Table 1). Finally, the successfully constructed ppk mutant was named as PPK4320.

\section{Construction of the ppk-complemented strain}

Firstly, a gentamycin-resistant gene was amplified by using PCR from suicide vector PJQ200SK with the primers of pGMF and pGMR (Table 1) to obtain a selection gene. The amplified DNA fragment was inserted into the ScaI restriction enzyme sites of the ampicillin-resistant gene in pBR322 to generate pBR322Gm. Secondly, the ppk gene was amplified with the primers, pkF containing an EcoR V enzyme site and pkR containing a BamH I enzyme site (Table 1). Then, the DNA fragment was subcloned into the tetracycline resistance gene between the EcoR V and BamH I sites of pBR322Gm. At last, the recombinant plasmid was named as pBR322Gm-ppk and then transformed into the ppk knockout mutant to generate the ppk-complemented strain PPK4320C. The growth curves of the mutant strain PPK4320, wild-type strain and PPK4320C in Luria-Bertani (LB) broth medium were determined by measuring the optical density (OD) $600 \mathrm{~nm}$ at different points in time.

\section{Western blotting analysis of the PPK expression}

The production of the PPK protein after ppk gene mutation and complementation was detected by Western blotting as follows: $10 \mathrm{ml}$ of overnight cell culture was resuspended in $1 \mathrm{ml}$ lysis buffer [lysis buffer ( $\mathrm{pH} 8.0$ ): $50 \mathrm{mM}$ Tris- $\mathrm{HCl}, 2 \mathrm{mM}$ EDTA, $100 \mathrm{mM} \mathrm{NaCl}, 0.5 \%$ Triton $\mathrm{X}-100$, lysozyme $0.1 \mathrm{mg} / \mathrm{Ml}, 1 \mathrm{mM} \mathrm{PMSF}]$. The samples were sonicated in a ice bucket for $3 \times 10 \mathrm{~s}$ and then centrifuged for $5 \mathrm{~min}$ at $13,000 \mathrm{rpm}$ at $4{ }^{\circ} \mathrm{C}$. Ten microliters of supernatant was used for protein quantification. The protein samples were separated by sodium dodecyl sulfatepolyacrylamide gel electrophoresis (SDS-PAGE) on a $10 \%$ polyacrylamide resolving gel. Then, the electrophoresed proteins were transferred to a PVDF membrane and incubated for $1 \mathrm{~h}$ at room temperature with $5 \%$ fat-free milk. The membrane was incubated overnight at $4{ }^{\circ} \mathrm{C}$ with primary antibody. After being washed at room temperature for 30-60 min with 5 or more changes of PBST wash buffer, the membrane was incubated for $1 \mathrm{~h}$ at room temperature with goat anti-rabbit IgG-HRP secondary antibody. Then, the membrane was washed for 30-60 min with 5 or more changes of PBST wash buffer. Finally, the member was detected with chemiluminescent detection substrate and exposed to film. Then, its image was developed.

\section{Measurement of the poly $P$ levels}

Detection of poly P levels in the wild-type, PPK4320 and PPK4320C was performed as described previously [11]. Bacteria were grown in LB medium at $37^{\circ} \mathrm{C}$ for $18 \mathrm{~h}$. Triplicate $1 \mathrm{ml}$ aliquots of cells were collected and pelleted by centrifugation at 10,000 rpm for $2 \mathrm{~min}$. To the pellets was added $500 \mu \mathrm{L}$ of $4 \mathrm{M}$ guanidine isothiocyanate (GITC) lysis buffer (4 M GITC, $500 \mathrm{mM}$ Tris-HCl, $\mathrm{pH}$ 7.0) prewarmed at $95{ }^{\circ} \mathrm{C}$. The pellets were vortexed, incubated for $5 \mathrm{~min}$ at $95{ }^{\circ} \mathrm{C}$ and sonicated briefly. Protein quantitation was performed by using the Protein Quantitation Kit (TIAN GEN Biotechnology Co. Ltd, China). Then, to each tube, $30 \mu \mathrm{L}$ of $10 \%$ sodium dodecyl sulfate, $500 \mu \mathrm{L}$ of $95 \%$ ethanol and $10 \mu \mathrm{L}$ of glassmilk (Bio 101, CA, USA) were added. After being vortexed, the tube was centrifuged briefly, and then, the pellet was suspended in $500 \mu \mathrm{L}$ of cold New Wash buffer (5 mM Tris-HCl [pH 7.5], $50 \mathrm{mM}$ $\mathrm{NaCl}, 5 \mathrm{mM}$ EDTA and $50 \%$ ethanol). This step was repeated three times. The washed pellet was resuspended in $50 \mu \mathrm{L}$ of $50 \mathrm{mM}$ Tris- $\mathrm{HCl} \mathrm{pH} \mathrm{7.4,} 10 \mathrm{mM} \mathrm{MgCl}_{2}$ and $20 \mu \mathrm{g}$ each of DNase and RNase per milliliter and incubated at $37{ }^{\circ} \mathrm{C}$ for $10 \mathrm{~min}$. The pellet was first washed with $150 \mu \mathrm{L}$ of $4 \mathrm{M}$ GITC lysis buffer and $150 \mu \mathrm{L}$ of $95 \%$ ethanol and then twice in New Wash buffer. Poly $\mathrm{P}$ was eluted from the glassmilk pellet with $50 \mu \mathrm{L}$ of $50 \mathrm{mM}$ Tris $-\mathrm{HCl}$ (pH 8.0) at $95{ }^{\circ} \mathrm{C}$ for $2 \mathrm{~min}$, followed by two additional elutions. Subsequently, a toluidine blue O (TBO) method was used to measure the poly $\mathrm{P}$ levels. A standard poly $\mathrm{P}$ curve was made by serially diluting a solution of a known quantity of sodium poly $\mathrm{P}$ (Sigma-Aldrich) and adding $100 \mu \mathrm{L}$ aliquots to $900 \mu \mathrm{L}$ of 6-mg/L TBO dye (SigmaAldrich) in $40 \mathrm{mM}$ acetic acid. After incubation at room temperature for $15 \mathrm{~min}$, OD530 $\mathrm{nm}$ and OD630 $\mathrm{nm}$ were measured, and the amount of poly $\mathrm{P}$ was expressed as the ratio of OD530 nm to OD630 nm. The poly P concentrations of wild-type, PPK4320 and PPK4320C were measured by comparing the ratio of OD530 $\mathrm{nm}$ to OD630 nm with the standard curve. Poly $\mathrm{P}$ quantity in cells was expressed in micrograms of poly $\mathrm{P}$ per milligram of total cellular protein.

\section{Stress tolerance assays}

Bacteria were grown for $18 \mathrm{~h}$ in $\mathrm{LB}$ at $37^{\circ} \mathrm{C}$. For the oxidative stress assay, cells were collected and washed with 
phosphate-buffered saline (PBS) and then diluted to an OD600 of 1.0. $\mathrm{H}_{2} \mathrm{O}_{2}$ was added into the bacterial suspension at final concentrations of $0,20,40,60,80$ and $100 \mathrm{mmol} / \mathrm{L}$ and incubated at $37{ }^{\circ} \mathrm{C}$ for $15 \mathrm{~min}$. Then, $100 \mu \mathrm{L}$ of samples was withdrawn, diluted in PBS and plated on non-swarming LB agar plates to determine viable cell numbers. For the osmotic challenge, bacteria were collected, suspended and diluted to $10^{7}$ cells $/ \mathrm{mL}$ in PBS. Then, the samples were mixed with an equal volume of $4.8 \mathrm{~mol} / \mathrm{L} \mathrm{NaCl}$ (final concentration: $2.4 \mathrm{~mol} / \mathrm{L}$ ) and incubated at $37{ }^{\circ} \mathrm{C}$. Samples collected at $0,0.5,1,1.5$ and $2 \mathrm{~h}$ were diluted and plated on non-swarming LB agar plates to determine viable cell numbers. For the heat resistance test, the PPK4320, PPK4320C and wild-type bacteria were centrifuged, resuspended in PBS and incubated at $56{ }^{\circ} \mathrm{C}$ for 0 , 2, 4, 6 and $8 \mathrm{~min}$. Samples were collected at the different time points, diluted and plated on non-swarming LB agar plates to determine viable cell numbers. All survival rates under stress conditions were determined by the number of viable cells after exposure to stress divided by the viable cell numbers before exposure to stress [5, 6].

\section{Cell adhesion and invasion assays}

The 5637 cells (human urothelial bladder cell line) were grown in 1640 medium supplemented with $10 \%$ heatinactivated fetal bovine serum, penicillin $\mathrm{G}(50 \mu \mathrm{g} / \mathrm{mL})$ and streptomycin $(100 \mu \mathrm{g} / \mathrm{mL})$ at $37{ }^{\circ} \mathrm{C}$ in $5 \% \mathrm{CO}_{2}$. The adhesion assay was performed according to previously reported methods [12]. Confluent monolayers of 5637 cells in 24-well plates (approximately $10^{5}$ cells/well) were incubated with bacteria $\left[10^{7}\right.$ colony-forming units $(\mathrm{CFU}) /$ well $]$ for $3 \mathrm{~h}$. After incubation, the monolayers were washed four times with PBS and then suspended in $0.5 \%$ Triton X-100 for $8 \mathrm{~min}$. The numbers of bacteria were counted on non-swarming agar plates. Adhesion was expressed as the percentage of adherent bacteria versus total bacteria added.

For the invasion assay, the invasion of 5637 cells by bacteria was performed as described in a previous study [6, 13]. Briefly, confluent monolayers of epithelial cells in 24 -well plates $\left(10^{5}\right.$ cells/well $)$ were incubated with bacteria $\left(10^{7} \mathrm{CFU} /\right.$ well $)$ for $1.5 \mathrm{~h}$. The monolayers were washed with PBS and then incubated with non-serum 1640 medium containing gentamicin $(100 \mu \mathrm{g} / \mathrm{mL})$ for another 1 , 2 and $3 \mathrm{~h}$ at $37^{\circ} \mathrm{C}$ to eliminate the extracellular bacteria. To determine the number of intracellular bacteria, the monolayers were washed with PBS and lysed with $0.5 \%$ Triton $\mathrm{X}-100$. The released intracellular bacteria were determined by serial dilution and plating on non-swarming agar plates. The results are expressed as the percentage of viable bacteria that survived the gentamicin treatment versus the total bacteria added.

\section{Mouse model of UTI}

The C57BL/6 mouse model of UTI was established according to methods described previously with minor modifications [5, 14]. Briefly, 7-week-old female C57BL/6 mice were deeply anesthetized with an intraperitoneal injection of $10 \%$ chloral hydrate $(4 \mu \mathrm{L} / \mathrm{g})$. Prior to infection, the urinary bladders of the mice were voided by gentle compression of the abdomen. Then, the mice were inoculated transurethrally with a $50 \mu \mathrm{L}$ suspension of $2-5 \times 10^{10}$ $\mathrm{CFU} / \mathrm{mL}$ of the wild-type strain, PPK4320, or PPK4320C using a venous indwelling needle (24G) and a microinjector $(100 \mu \mathrm{L})$. Controls were injected with sterile PBS. At $48 \mathrm{~h}$ post-infection, the bladders of the mice were aseptically removed, divided into two parts and weighed. One part of the bladder was homogenized in $0.5 \mathrm{~mL}$ sterile PBS and was used for viable colony-forming unit counts and an inflammatory factors test using enzyme-linked immunosorbent assay (ELISA). The other portion was used for histological analysis. The viable counts were determined as $\mathrm{CFU}$ per gram of bladder tissue. The limit of detection of viable CFU counting was $10^{2} \mathrm{CFU} / \mathrm{g}$ bladder tissue. This animal study was approved and performed in accordance with guidelines of the Committee for Animal Studies at Guangzhou Medical University.

\section{Cytokine testing and histological analysis}

One part of the collected bladder tissue was homogenized and $100 \mu \mathrm{L}$ of the homogenate was used for viable counts determination. The remaining homogenate was centrifuged at $10,000 \mathrm{rpm}$ for $10 \mathrm{~min}$. The supernatant was collected and used for an ELISA determination of the inflammatory factors tumor necrosis factor-alpha (TNF- $\alpha$ ) and interleukin-6 (IL-6), according to the manufacturer's instructions (MultiSciences (Lianke) Biotech). The other part of the bladder was immersion-fixed overnight in $4 \%$ paraformaldehyde, embedded in paraffin, cut into 5 - $\mu$ m-thick sections and stained with hematoxylin and eosin for histological evaluation.

\section{Swarming and biofilm formation assays}

The swarming assay was performed as described in a previous study [15]. Briefly, $5 \mu \mathrm{L}$ of a bacteria culture was inoculated in the center of the surface of swarming plate agar (containing $1.5 \% \mathrm{~W} / \mathrm{V}$ agar and $5 \% \mathrm{~V} / \mathrm{V}$ defibrinated sheep blood) and incubated at $37{ }^{\circ} \mathrm{C}$. The swarming migration distances were quantified by following the swarm fronts of the wild-type strain and $p p k$ mutant cells and recording the progress at 1 -h intervals.

The biofilm assay was performed as described by Esther Heikens et al. with minor modifications [16]. In brief, 
bacteria were cultured in LB medium for $18 \mathrm{~h}$ at $37{ }^{\circ} \mathrm{C}$ with shaking. Then, for each well of a 96 -well polystyrene microtiter plate, two hundred $\mu \mathrm{L}$ of LB medium mixed with $10 \mu \mathrm{L}$ of $\left(1 \times 10^{7} \mathrm{CFU}\right)$ cultured bacterial suspension were added in triplicate and incubated for $12 \mathrm{~h}$ at $37{ }^{\circ} \mathrm{C}$. Every $2 \mathrm{~h}$ after incubation, the bacteria were removed and the wells were washed with $200 \mu \mathrm{L}$ PBS. The plates were dried for $1 \mathrm{~h}$ at room temperature. The bacteria were fixed with methanol for $30 \mathrm{~s}$. Then, $100 \mu \mathrm{L}$ of $1 \%$ Gram's crystal violet solution was added to each well. After $30 \mathrm{~min}$, the stain was removed and the plates were washed three times with $200 \mu \mathrm{L}$ of PBS. The Gram's crystal violet was extracted with a $100 \mu \mathrm{L}$ solution of ethanol/acetone mixture (volume of ethanol: acetone $=80: 20$ ). Two hundred $\mu \mathrm{L}$ of extraction samples was added into the new wells of the 96-well plate. The absorbance at $570 \mathrm{~nm}$ was measured directly with an ELISA reader.

\section{Proteome analysis}

Sample Preparation. Protein extraction and two-dimensional gel electrophoresis (2-DE) were performed using methods described previously $[12,17]$ with minor modifications. Briefly, $P$. mirabilis $\mathrm{H} 4320$ and the mutant PPK4320 were cultured in LB medium for $18 \mathrm{~h}$ with shaking. The bacterial cells were harvested by centrifugation at $8000 \mathrm{rcf}$ for $10 \mathrm{~min}$. The pellets were mixed with lysis buffer containing protease inhibitor and lysozyme. Then, the mixtures were lysed using an ultrasonic wave $(5 \mathrm{~s}$ on $/ 5 \mathrm{~s}$ off at $37 \%$ intensity for $5 \mathrm{~min}$ ) and held in an ice bath. Samples were centrifuged at 20,000 rcf for $45 \mathrm{~min}$ at $4{ }^{\circ} \mathrm{C}$, and the supernatants were collected. The protein samples were purified with an Amershan cleanup kit and quantitated with a GE 2-D Quant Kit (according to the manufacturer's instructions).

2-DE. The protein extraction was dissolved in rehydration buffer (7 M urea, $2 \mathrm{M}$ thiourea, $4 \%$ CHAPS3 [w/v], $40 \mathrm{mM}$ DTT, $1 \% \mathrm{pH}$ 4-7 immobilized $\mathrm{pH}$ gradient [IPG] buffer and $1 \%$ bromophenol blue solution). The first and second dimensions of the PAGE were performed at least three times. Solubilized total protein samples $(450 \mu \mathrm{L}$ each) were loaded onto 24-cm IPG strips ( $\mathrm{pH} 4-7$ ). The rehydration and isoelectric focusing (IEF) were performed according to the manufacturer's instructions using an Ettan IPGphor II apparatus (Amersham Biosciences, Sweden). The second-dimension SDS-PAGE was performed with $12.5 \%$ resolving gels and $5 \%$ stacking gels using an Ettan DALT six instrument (Amersham Biosciences). The gels were stained with staining solution (Coomassie R-350 $0.025 \%$ and Glacial acetic acid $10 \%$ ). The resolved proteins in gels were scanned using an ImageScanner II (Amersham Biosciences) and were analyzed with ImageMaster V5.0 software. Only those protein spots with differences in density of 1.5 -fold or greater between the groups were selected. In-Gel Protein Digestion. Protein bands were excised from preparative Coomassie blue-stained gels and washed several times with destaining solutions $\left(25 \mathrm{mM} \mathrm{NH} \mathrm{NCO}_{3}\right.$ for $15 \mathrm{~min}$ and then $50 \%$ acetonitrile containing $25 \mathrm{mM}$ $\mathrm{NH}_{4} \mathrm{HCO}_{3}$ for $20 \mathrm{~min}$ at $37{ }^{\circ} \mathrm{C}$ ). Then, gel pieces were dehydrated with $100 \%$ acetonitrile. Once dried, $10 \mu \mathrm{L}$ of $12.5 \mathrm{ng} / \mu \mathrm{L}$ trypsin diluted in $25 \mathrm{mM} \mathrm{NH}_{4} \mathrm{HCO}_{3}$ was added over the gel spots, and the solution was incubated for $45 \mathrm{~min}$ at $4{ }^{\circ} \mathrm{C}$. The redundant trypsin solution was absorbed away, and $10 \mu \mathrm{L}$ of $25 \mathrm{mM} \mathrm{NH}_{4} \mathrm{HCO}_{3}$ was added over the gel spots and incubated overnight at $37^{\circ} \mathrm{C}$.

\section{Protein identification}

Extraction was performed in two steps by the additions of $50 \%$ acetonitrile and $0.1 \%$ trifluoroacetic acid. The pooled extract was dried and dissolved in a $3 \mu \mathrm{L}$ matrix (5 $\mathrm{mg} / \mathrm{mL}$ recrystallized $\alpha$-cyano-4-hydroxy-cinnamic acid) and spotted on an MS sample plate. Mass analysis was performed using an Ultraflex III-MALDI TOF/TOF Mass Spectrometer (Bruker, Germany). The peptide mass spectrum was obtained in positive ion reflector mode. Monoisotopic peak masses were limited within the range of 700-3500 Da. Trypsin autolysis peptides of mass 842.5 were used as internal standards. Four of the most intense ion signals were automatically selected as precursors for MS/MS acquisition, excluding the trypsin autolysis peaks and matrix ion signals. The peptide mass fingerprint combined with the MS/MS spectra data was searched against the NCBI database using Biotools software and MASCOT (Matrix Science).

\section{Statistical analysis}

All values are expressed as mean \pm standard deviation. Statistical analysis was performed with one-way ANOVA by using SPSS 13.0 software. Differences with $P<0.05$ were considered to be statistically significant.

\section{Results}

\section{$p p k$ is important for poly $\mathrm{P}$ synthesis of $P$. mirabilis}

To determine the role of PPK in the pathogenesis of $P$. mirabilis UTI, the $p p k$ gene was inactivated by insertion of a kanamycin cassette (about $2 \mathrm{~kb}$ ). As shown in Fig. 1a, the size of PCR-amplified DNA fragment for the wildtype and mutant strain was about 4 and $6 \mathrm{~kb}$, respectively. This result suggested that the intron had been inserted into the $p p k$ gene successfully. DNA sequencing result suggested that the intron was inserted at a correct location 


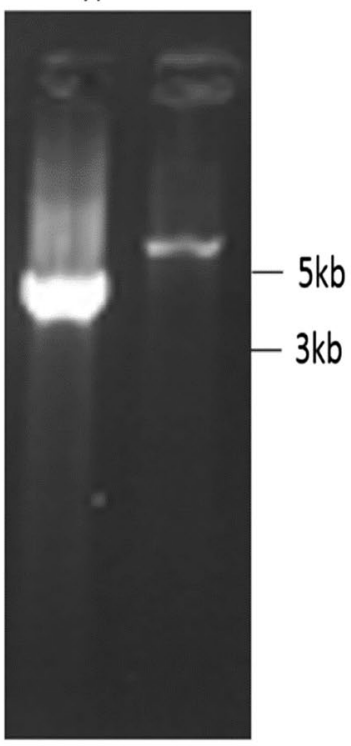

B
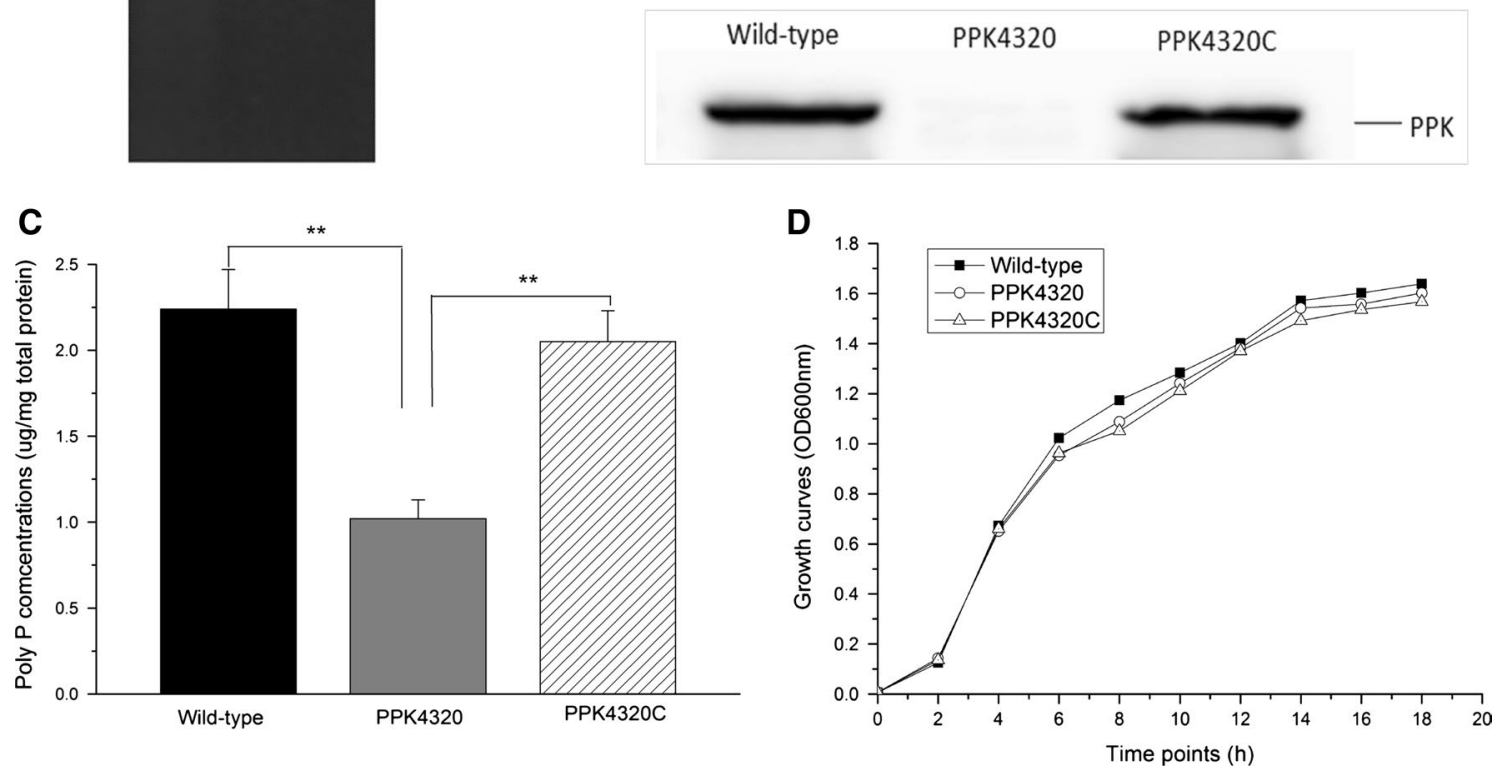

Fig. 1 PPK protein and poly P production of the wild-type, PPK4320 and PPK4320C. Bacteria total protein was extracted from overnight $(18 \mathrm{~h}) \mathrm{LB}$ broth cultures. a PCR verification of intron insertion with the primers ppk-outF and ppk-outR. b Western blot test-

(data not shown). The PPK protein production was shown to be an undetectable level in the ppk mutant by Western blot analysis. After transformation with the $p p k$ complementation plasmid, the PPK expression of the $p p k$ mutant was almost recovered to a level of the wild-type (Fig. 1b). PPK has been shown to be associated with the poly P synthesis $[6,9]$. Similar results were obtained through detection of poly P. As shown in Fig. 1c, when the ppk gene was disrupted, the poly P level of the P. mirabilis declined significantly. The mutant PPK4320 and the ppk complementation strain PPK4320C showed no significant growth defects in vitro compared to the wild-type (HI4320) when the three strains were grown independently in LB medium (Fig. 1d).

ing of the PPK protein expression. c Poly P levels analysis. Values are expressed as the quantity of poly $\mathrm{P}(\mu \mathrm{g})$ per milligram of total cellular protein. d Examination of the growth curves. $* P<0.05$, $* * P<0.01$

\section{$p p k$ is important for stress tolerance of $P$. mirabilis}

After exposure to $\mathrm{H}_{2} \mathrm{O}_{2}$ at different concentrations for 15 min, the survival rates of PPK4320 were significantly lower than those of the wild-type and PPK4320C $(P<0.01)$ (Fig. 2a). To test the survival under osmotic stress, bacteria were exposed to $2.5 \mathrm{~mol} / \mathrm{L} \mathrm{NaCl}$ for 0.5 , $1,1.5$ and $2 \mathrm{~h}$ and then plated on LB agar plates. The survival rates of HI4320 were $65.78 \pm 9.77,46.72 \pm 6.60$, $23.59 \pm 5.64$ and $16.37 \pm 1.82 \%$ at $0.5,1,1.5$ and $2 \mathrm{~h}$, respectively. However, the survival rates of PPK 4320 reduced to $33.38 \pm 3.80,15.76 \pm 1.20,9.41 \pm 2.00$ and $7.61 \pm 1.66 \%$ at $0.5,1,1.5$ and $2 \mathrm{~h}$, respectively $(P<0.01$ when compared with HI4320 and PPK4320C). The 

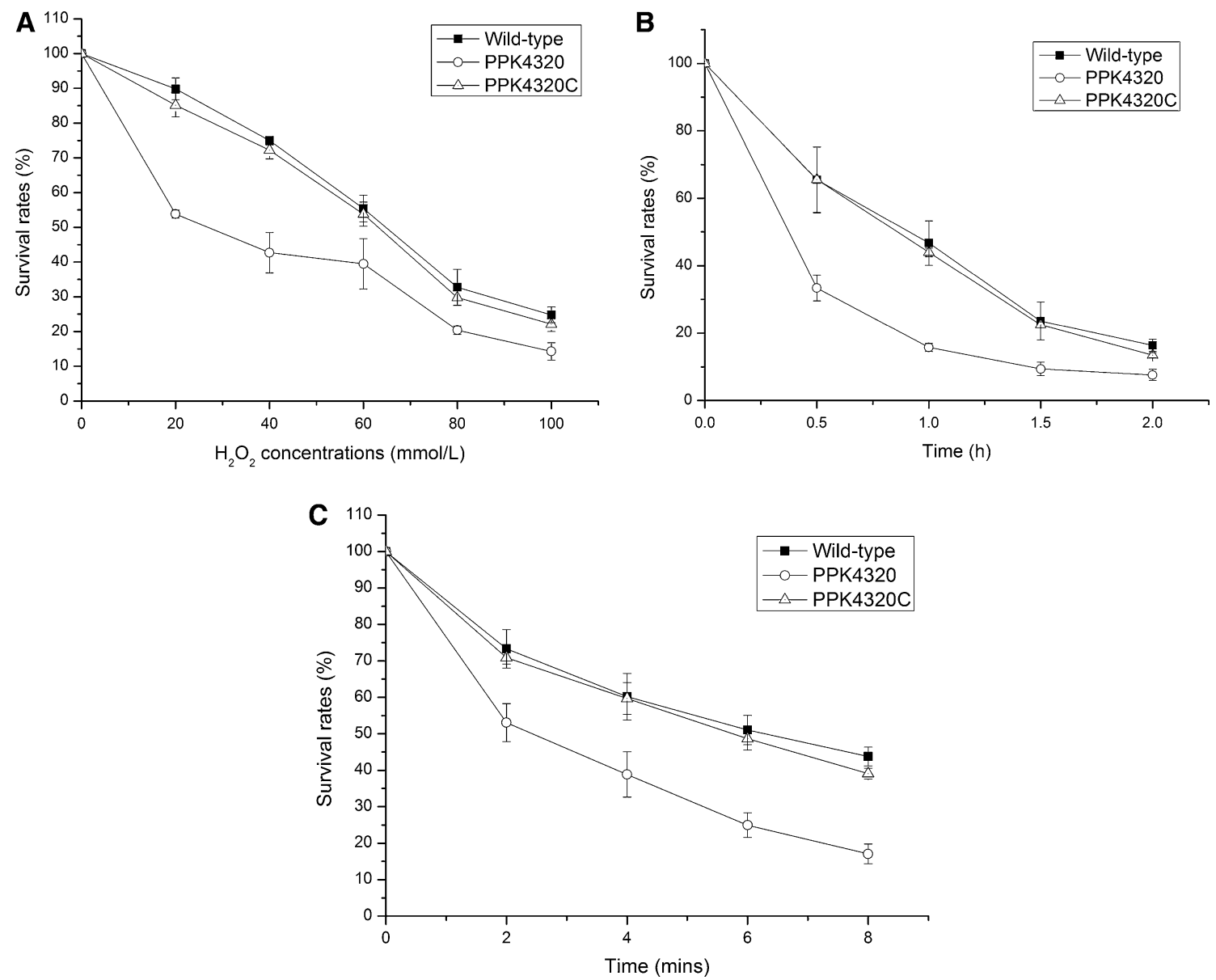

Fig. 2 Survival assays. a The survival rates of the ppk mutant PPK4320 compared with the parent strain P. mirabilis HI4320 and ppk complementation strain PPK4320C after exposure to oxidative stress. b The survival rates of the PPK4320 compared with those of the wild-type and PPK4320C under a high osmolarity challenge. c The survival rates of the PPK4320 compared with the wild-type bacteria and PPK4320C under heating conditions survival rates of PPK4320C were restored to $65.54 \pm 9.68$, $43.97 \pm 1.26,22.46 \pm 0.85$ and $13.45 \pm 0.73 \%$ at 0.5 , $1,1.5$ and 2 h, respectively (Fig. 2b). For the heat resistance test, PPK4320 and the wild-type strain were incubated at $56{ }^{\circ} \mathrm{C}$ for $0,2,4,6$ and $8 \mathrm{~min}$. Similar to the results of oxidative and osmotic stress tests, the ppk mutant was deficient in survival under heat stress conditions compared with the wild-type and PPK4320C $(P<0.01)$ (Fig. 2c). These results suggest that $p p k$ is important for $P$. mirabilis HI4320 to resist environmental stresses.

\section{ppk mutant is deficient in adhesion to and invasion of uroepithelial cells}

Adhesion to uroepithelial cells and subsequent colonization of tissues are important for P. mirabilis to resist urine flow and to establish a further infection. Invasion of the cells is helpful for P. mirabilis to evade immune attacks and to persist in tissues. So the effects of the ppk mutation on $P$. mirabilis adhesion and invasion of bladder uroepithelial cells were examined. As shown in Fig. 3a, the adhesion of uroepithelial cells for PPK4320 was significantly less than that of the wild-type or PPK4320C $(P<0.01)$. Furthermore, the capability of PPK4320 to invade uroepithelial cells was also lower than that of the wild-type strain at 1,2 and $3 \mathrm{~h}$, respectively $(P<0.01)$ (Fig. $3 \mathrm{~b})$.

\section{ppk inactivation leads to a less colonization of bladder tissue in mouse models for $P$. mirabilis HI4320}

To evaluate the role of $p p k$ in UTIs caused by $P$. mirabilis, female C57BL/6 mice were used as the in vivo study model. As shown in Fig. 4, after $48 \mathrm{~h}$ of inoculation with PPK4320 for 20 mice, only 14 mice had the level of bacterial colonization more than $10^{2} \mathrm{CFU} / \mathrm{g}$ bladder tissue. However, seventeen or eighteen mice had this level of 


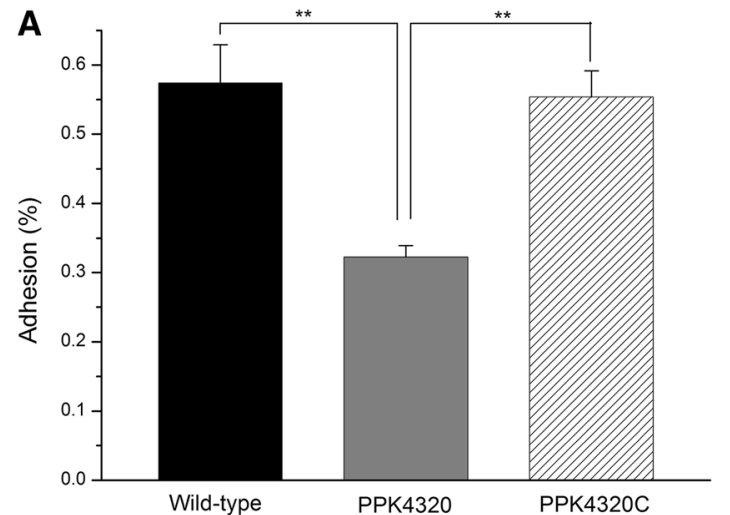

Fig. 3 Wild-type, PPK4320, or PPK4320C adhesion or invasion of 5637 cells. a 5637 cell monolayers were incubated with equivalent amounts of the parent strain, the PPK4320 and PPK4320C for $3 \mathrm{~h}$. A standard adhesion assay was performed as described in the "Materi-

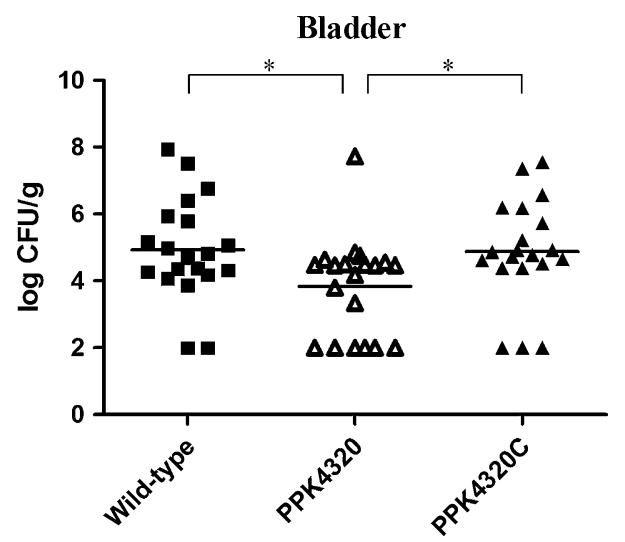

Fig. 4 Quantitative bacterial counts in bladders of mice challenged with either the wild-type, PPK4320 and PPK4320C. Each square or triangle represents CFU per gram of bladder tissue from an individual mouse. Horizontal lines represent the geometric means of the colony counts. $* P<0.05$

colonization in twenty mice infected with PPK4320 or the wild-type strain, respectively. The amounts of bacteria colonization in bladders of the PPK4320-infected mice were also significantly less than those of the wild-type-infected or PPK4320C-infected animals. These results indicate that $p p k$ is important for the colonization and survival of $P$. mirabilis in the bladder.

\section{The ppk gene is important for $P$. mirabilis to induce urinary tract inflammation in mice}

Because TNF- $\alpha$ and IL- 6 are both important cytokines contributing to the host immune system against bacterial infection [18-20], we examined these cytokines in the bladder tissues of the experimental mice using the ELISA

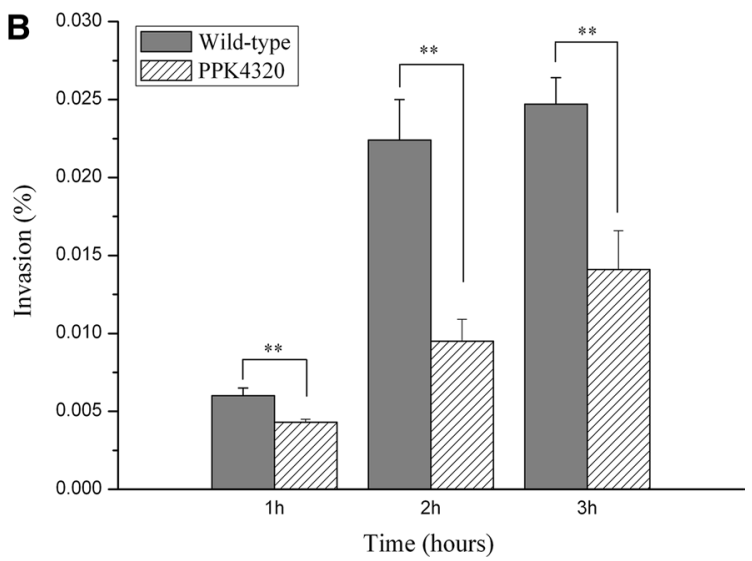

als and methods" section. b Invasion of 5637 cells for the wild-type strain or PPK4320 at 1, 2 and $3 \mathrm{~h}$. Values are the means of at least three independent assays. Error bars indicate standard deviations. $* * P<0.01$

method. As shown in Fig. 5a, the TNF- $\alpha$ level in bladders of the wild-type-infected mice $(501.70 \pm 57.86 \mathrm{pg} /$ $\mathrm{mL})$ and PPK4320C $(485.22 \pm 40.91 \mathrm{pg} / \mathrm{mL})$ was significantly higher than those of mice infected with the $p p k$ mutant $(388.13 \pm 19.03 \mathrm{pg} / \mathrm{mL})$. Additionally, the IL-6 levels in the mutant-challenged group $(209.00 \pm 45.72 \mathrm{pg} /$ $\mathrm{mL}$ ) were reduced compared to the wild-type-infected animals $(306.63 \pm 56.98 \mathrm{pg} / \mathrm{mL})$ and PPK4320C (292.81 \pm 38.3 pg/mL) (Fig. 5b).

Moreover, histologic examination of the bladders with hematoxylin and eosin staining also indicated that $p p k$ was correlated with inflammation in P. mirabilis-induced UTI. As shown in Fig. 5c, the bladder submucosa of mice with the wild-type or PPK4320C infection became obviously hydropic and hyperemic, and the mucous layers had large numbers of neutrophil infiltrations. In contrast, less histological alteration was observed in the bladder tissues of the mice infected with the $p p k$ mutant. These results indicate that $p p k$ plays a key role in the inflammation response of $P$. mirabilis-induced UTI.

\section{ppk mutation affects swarming and biofilm formation abilities of $P$. mirabilis}

Swarming migration is a property of $P$. mirabilis. The motility capacity is an advantage for $P$. mirabilis colonization within the urinary tract, related to the expression of virulence factors and to the capacity to invade urothelial cells [21]. The migration distances of the wild-type and PPK4320C strain at different time points were significantly longer than those of the ppk mutant PPK4320 when cultured on the blood agar plates $(P<0.05)$ (Fig. 6a, b). This result indicates that $p p k$ inactivation could impair the swarming motility of $P$. mirabilis. 

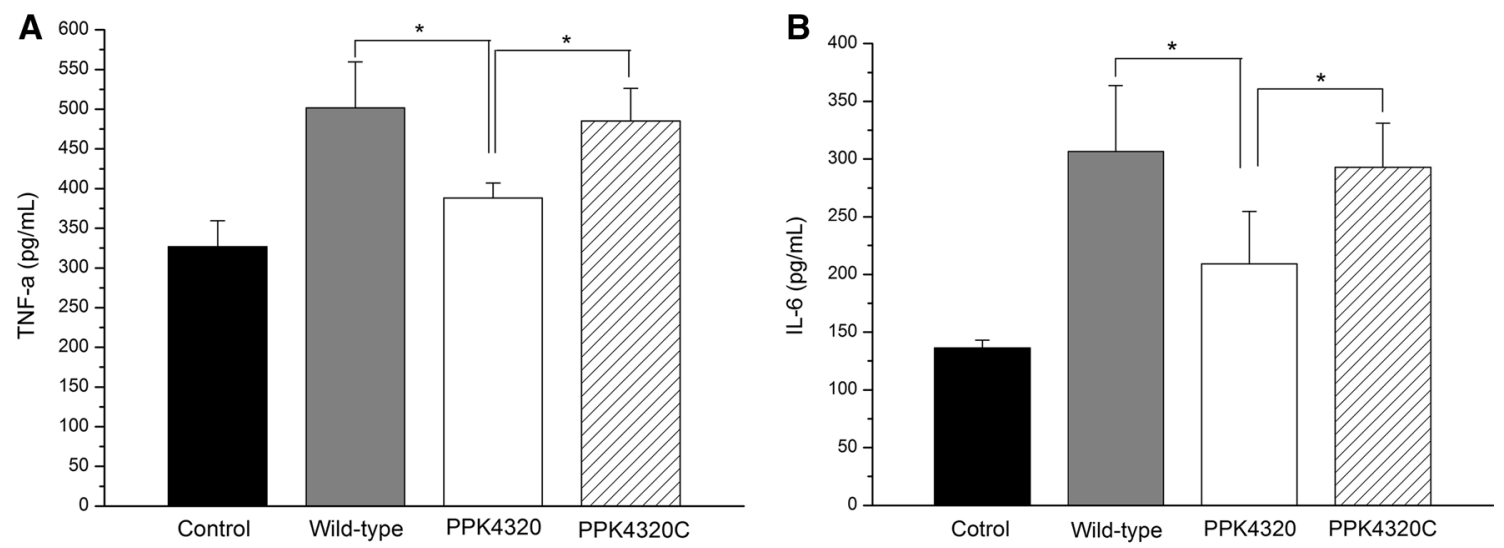

C

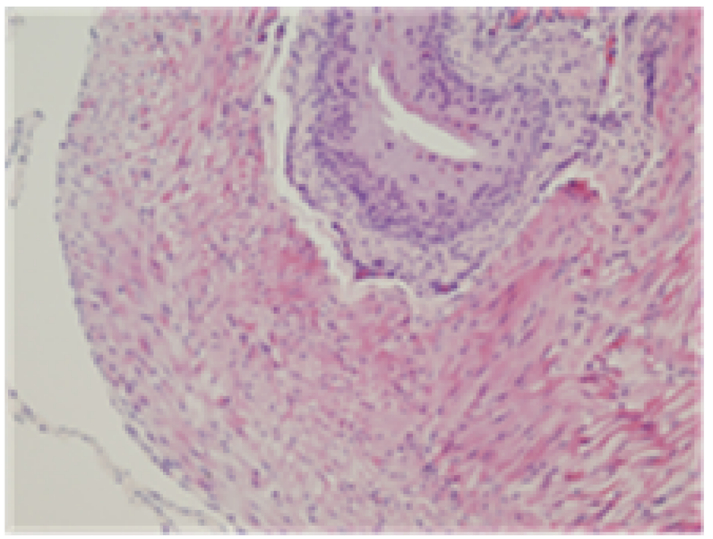

Control

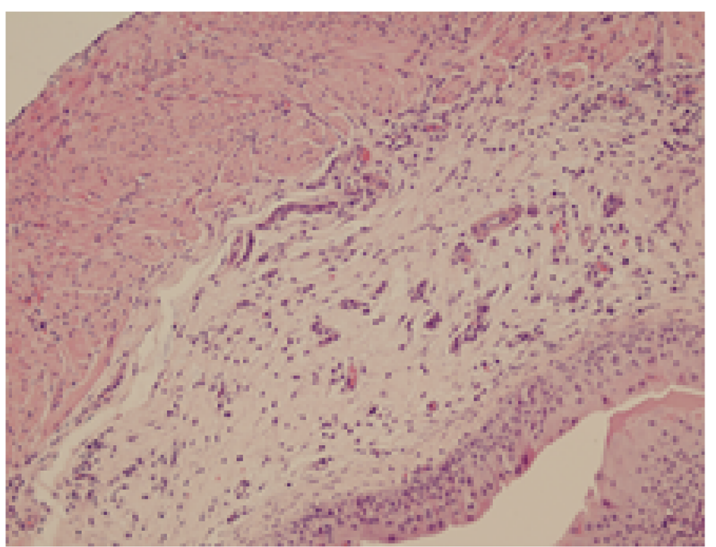

PPK4320

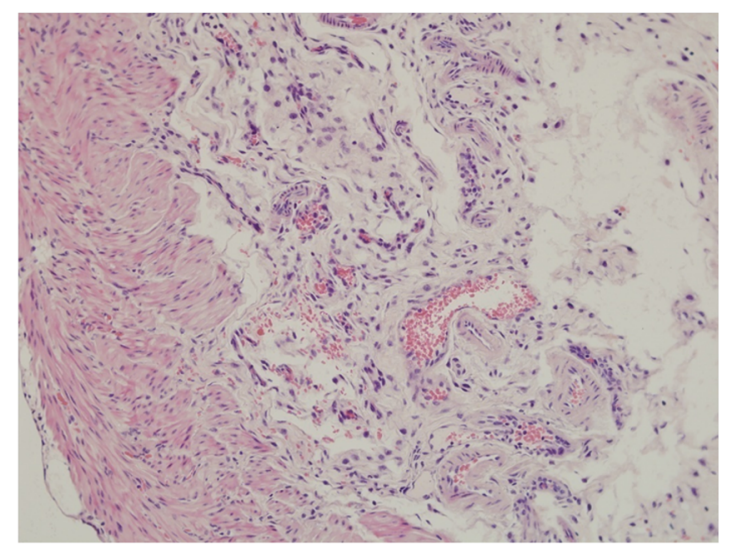

Wild-type

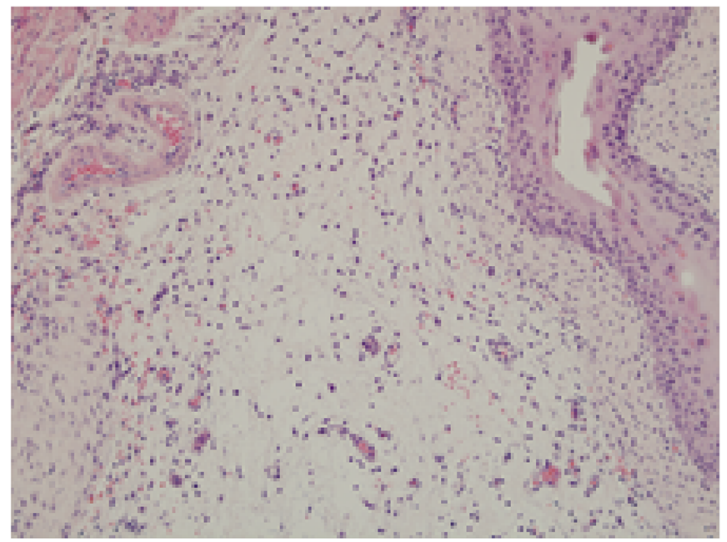

PPK4320C

Fig. 5 Inflammatory cytokine determinations and histological analysis of the bladder tissues in C57BL/6 mice infected with P. mirabilis. a TNF- $\alpha$ levels in the bladders of the mice. b IL- 6 levels in the blad-

ders of the mice. $\mathbf{c}$ Histological analysis of the bladder sections. The cytokine examination and histological analysis were performed as described in the "Materials and methods." $* P<0.05$

Because biofilm formation has been found to be related with survival in a host and indwelling device infections for P. mirabilis [22], biofilm formation was detected in this study. As shown in Fig. 6c, when ppk was interrupted, biofilm formation was significantly decreased, in contrast to those of the wild-type and ppk complementation strain $(P<0.01)$.

\section{$p p k$ is involved in regulation of virulence factors expression in $P$. mirabilis}

To verify whether $p p k$ is associated with protein expression regulation in $P$. mirabilis, we extracted the total protein from wild-type and $p p k$ mutant bacteria for analysis using 2-DE. The experiment was performed three times 


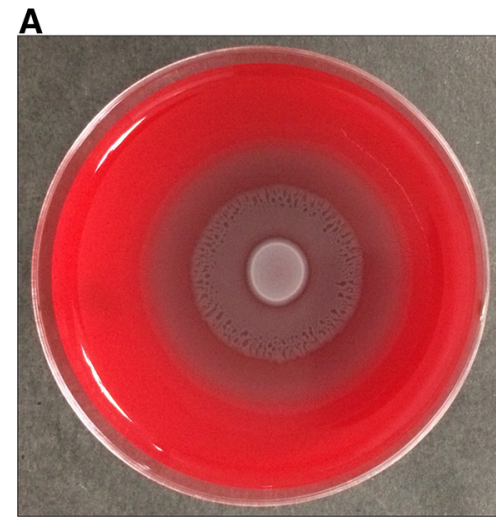

Wild-type

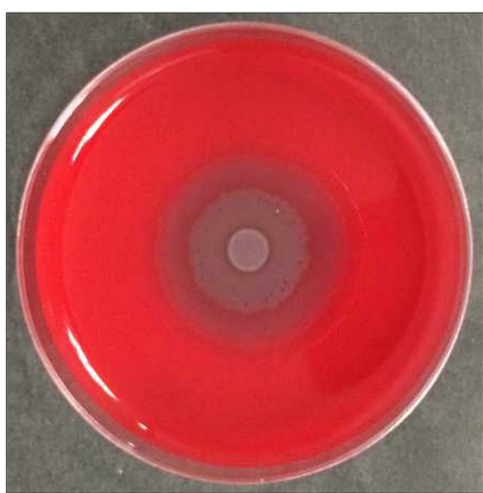

PPK4320

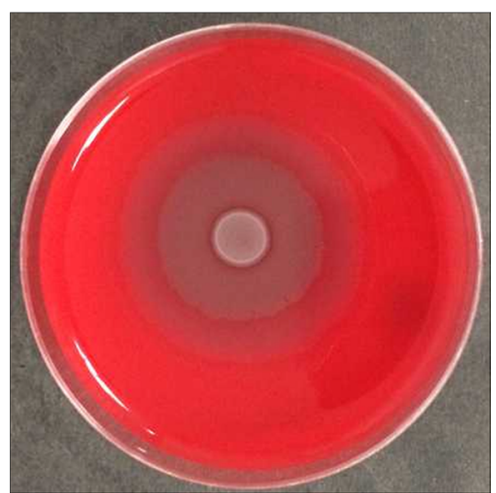

PPK4320C
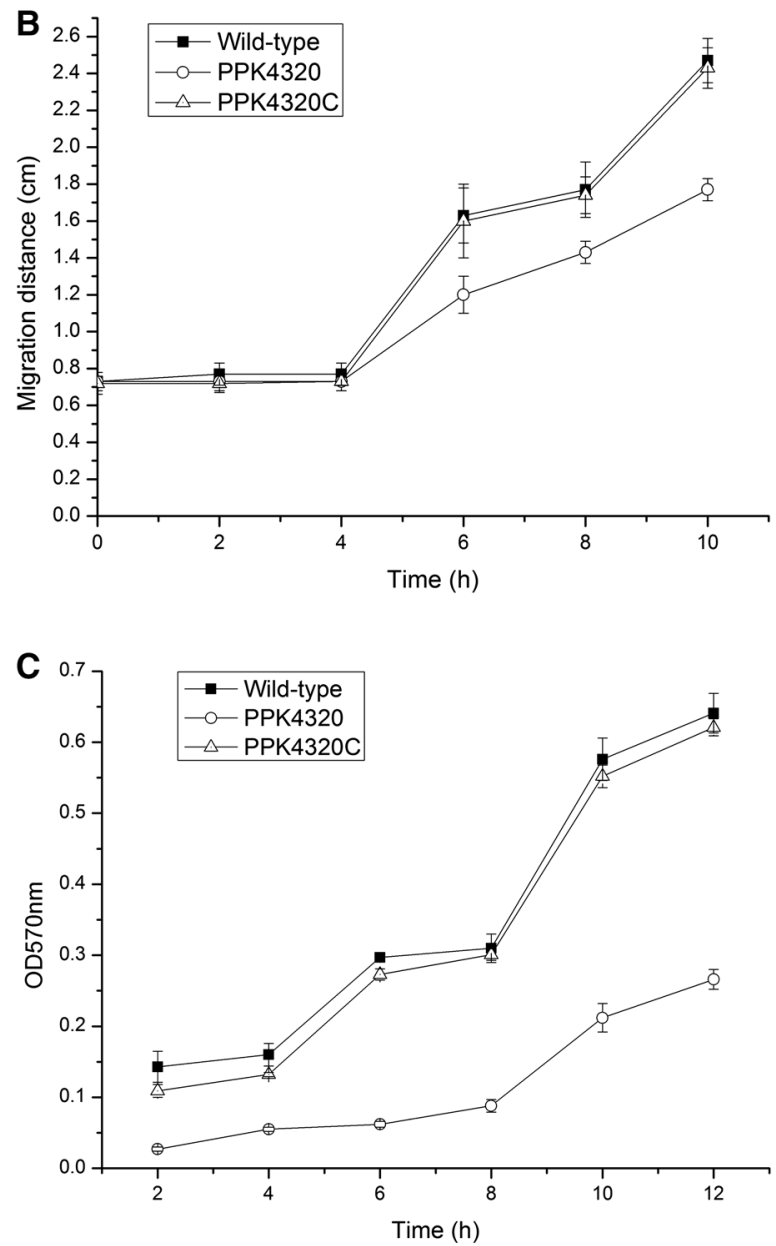

Fig. 6 Examination of swarming motility and biofilm formation. a Halo images of the bacteria swarming on blood agar plates. Aliquots $(5 \mu \mathrm{L})$ of overnight cultures were inoculated onto the centers of the plates and cultured at $37{ }^{\circ} \mathrm{C}$ for $10 \mathrm{~h}$. b Line graph showing the swarming migration distances of the wild-type, PPK4320 and PPK4320C. Aliquots $(5 \mu \mathrm{L})$ of overnight cultures were inoculated onto the centers of the swarming plates. The plates were incubated at $37{ }^{\circ} \mathrm{C}$, and the migration distances were measured hourly after inoculation. The data represent the means of three independent experiments with standard deviations. c Biofilm formation for wildtype, PPK4320 and PPK4320C. The biofilm level of the wild-type, PPK4320 and PPK4320C was determined as described in "Materials and methods." The optical density $(570 \mathrm{~nm})$ of the solution extracted with ethanol/acetone correlated with the level of biofilm formation 
Fig. 7 2-DE maps of the wildtype and the mutant PPK3420 bacteria. The up-regulated proteins are marked with U1-U4, and the down-regulated proteins are marked with D1-D7
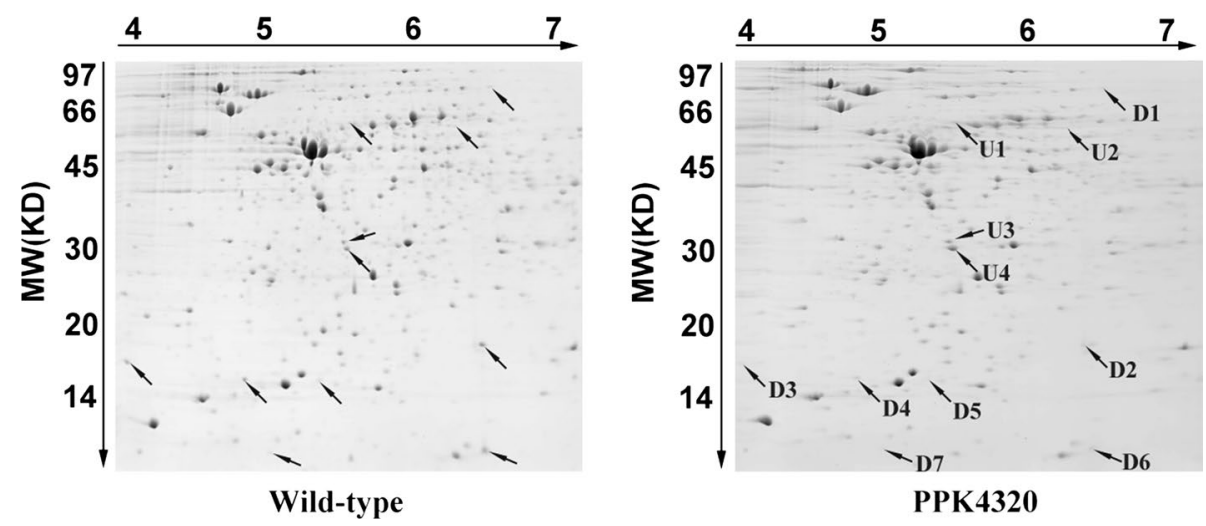

Table 2 List of protein spots identified by peptide mass fingerprinting

\begin{tabular}{|c|c|c|c|}
\hline Spot ID & Access number & Mass (kDa) & Protein name \\
\hline \multicolumn{4}{|c|}{ Down-regulation } \\
\hline D1 & gil194682214 & 74.0 & TonB-dependent receptor \\
\hline D2 & gil197285310 & 15.4 & Universal stress protein $\mathrm{G}$ \\
\hline D3 & gil197284171 & 18.0 & Major mannose-resistant/Proteus-like fimbrial protein \\
\hline D4 & gil197284852 & 17.3 & Heat shock protein \\
\hline D5 & gil197285480 & 52.3 & Flagellar capping protein \\
\hline D6 & gil194684989 & 11.0 & Putative membrane protein \\
\hline D7 & gil197284044 & 42.2 & Multidrug efflux protein \\
\hline \multicolumn{4}{|c|}{ Up-regulation } \\
\hline U1 & gil197284692 & 56.4 & Exported peptidase \\
\hline $\mathrm{U} 2$ & gil197286188 & 52.7 & Repressor protein for FtsI \\
\hline $\mathrm{U} 3$ & gil197286630 & 26.9 & FKBP-type peptidyl-prolyl cis-trans isomerase \\
\hline $\mathrm{U} 4$ & gil197284623 & 26.4 & Phosphotransferase \\
\hline
\end{tabular}

independently. Only spots showing the same patterns in three independent runs were retained and quantified using ImageMaster V5.0 software. Seven down-regulated and four up-regulated spots were identified in the gels of the ppk mutant protein profiles compared with those of the wild-type bacteria (according to the criteria described in the Materials and Methods section) (Fig. 7). The selected spots were excised and identified by LC-MS/MS. The seven down-regulated proteins were TonB-dependent receptor, universal stress protein $\mathrm{G}$, major mannose-resistant/Proteus-like fimbrial protein (MR/P fimbriae), heat shock protein, flagellar capping protein, putative membrane protein and multidrug efflux protein (Table 2). Additionally, the four up-regulated proteins were exported peptidase, repressor protein for FtsI, FKBP-type peptidyl-prolyl cis-trans isomerase and phosphotransferase. Among these proteins, $\mathrm{MR} / \mathrm{P}$ fimbriae have been identified as critical adhesins for P. mirabilis colonization of the urinary tract [23]. Flagellar capping protein, also known as FliD, is associated with pathogen adhesion capacity and motility [24, 25]. Universal stress protein $\mathrm{G}$ and heat shock protein are both important for the protection of cells against stress [26, 27]. These alterations in protein expression may explain why the functions of $P$. mirabilis changed in their stress resistance, adhesion and migration capacities after $p p k$ inactivation. We conclude that $p p k$ is involved in stress tolerance and virulence of $P$. mirabilis by regulating the expression of the proteins mentioned above.

\section{Discussion}

Poly polyphosphate (Poly P) is a linear chain inorganic phosphate linked by "high-energy" phosphoanhydride bonds [28] and is present in all species in nature [28, 29]. As a major poly $\mathrm{P}$ synthetic enzyme, poly $\mathrm{P}$ kinase, which reversibly catalyzes the polymerization of the terminal phosphate of ATP into a poly $\mathrm{P}$ chain, is associated with stress resistance and virulence in many pathogens [30]. However, the role of PPK in the pathogenesis of UTIs caused by $P$. mirabilis remains unknown. To address this issue, we constructed the $p p k$ isogenic insertional mutant of $P$. mirabilis HI4320 to test its biological functions using in vitro and in vivo models of UTI. 
When the ppk gene was interrupted by using an isogenic insertion of group II intron method, the expression of the PPK protein was shown to be blocked. And the poly P production of $p p k$ mutant PPK4320 was also reduced significantly compared to those of the wild-type and $p p k$ complementation strain PPK4320C. The PPK4320 was considerably less adherent and invasive to the urothelial cells and significantly less virulent in the colonization of mouse bladders compared to the wild-type and PPK4320C. UTIs involving bacteria can provoke the body's immune response and can induce the expression of inflammatory factors. IL- 6 and TNF- $\alpha$ are both important cytokines released during acute UTI [18-20]. The results of the ELISA analysis showed that the in vivo expression levels of cytokine IL-6 and TNF- $\alpha$ were significantly reduced in the $p p k$ mutantinfected bladders compared to the wild-type and ppk complementation strain-infected bladders. Histologic observation also demonstrated that the ppk mutant is ineffective in inducing bladder damage.

Proteus mirabilis encoding 17 putative fimbrial operons and five fimbrial types (ATFs, ambient-temperature fimbriae; MR/K, mannose-resistant Klebsiella-like; MR/P, mannose-resistant Proteus-like; NAFs, non-agglutinating fimbriae; and PMFs, Proteus mirabilis fimbriae) have been characterized [31]. Among the five types of fimbriae, $\mathrm{MR} / \mathrm{P}$ contributes to adhesion and invasion of the uroepithelial cells and bladder and kidney colonization [32-34]. Flagellar capping protein, also called the hook-associated protein 2 (HAP2), facilitates the polymerization of endogenous flagellin at the tips of the growing flagellar filaments. Previous studies have reported that flagellar capping protein is involved in mucin adhesion and UTI [24]. Using a proteomics analysis, we demonstrated that $P$. mirabilis $p p k$ is involved in the production of MR/P. These results indicated that ppk inactivation leads to an attenuated virulence (including cell adhesion and invasion, bladder and kidney colonization) and induces a tissue inflammatory response, which may be due to modulation of the expression of MR/P and flagellar capping protein.

Swarming and biofilm formation are both important for $P$. mirabilis for causing catheter-mediated urinary tract infections. Swarming motility allows $P$. mirabilis to migrate across catheters, gaining entry to the urinary tract $[1,35]$. The ppk mutant was deficient in swarming motility and had a decreased expression of flagellar capping protein. It has been previously reported that a mutation in the gene encoding flagellar capping protein prevented the assembly of normally synthesized FlaA flagellin monomers and resulted in the loss in motility and swarming differentiation [25]. We conclude that $p p k$ is important for the swarming capacity of P. mirabilis by affecting the production of flagellar capping protein. The $p p k$ gene has been identified to be related to the biofilm formation of the P. aeruginosa [8]. In this study, we also found that the biofilm formation of P. mirabilis was attenuated due to the $p p k$ interruption.

During the UTI development process, it is important for the pathogens to endure the stressful environment of the urinary tract. We found that the ppk mutant is defective in surviving oxidative, osmotic and heat stress conditions compared to the wild-type bacteria. The proteomics analysis results demonstrated that universal stress protein $\mathrm{G}$, heat shock protein and a putative membrane protein had low expression levels in the $p p k$ mutant. Universal stress protein $\mathrm{G}$ belongs to the universal stress protein superfamily and is involved in oxidative stress resistance [26]. Heat shock proteins are a group of proteins induced by heat shock and are known to be involved in temperature stress adaption and the folding and unfolding of other proteins [27]. These proteins are likely involved in the insufficient stress adaptation conferred by the ppk mutation in P. mirabilis.

In summary, the major finding of this study is that the $p p k$ gene, which is related to the poly $\mathrm{P}$ synthesis, plays an important role in stress tolerance and virulence of $P$. mirabilis in the urinary tract. However, the attenuation caused by the $p p k$ mutation might not be merely the result of the loss of stress resistance, swarming migration, biofilm formation and urinary tract colonization capacities but rather might be caused by the inability to properly regulate the production of other proteins, including some important virulence factors that directly mediate the pathogenic process of $P$. mirabilis-induced UTI.

Acknowledgments We would like to thank Prof. Harry L. T. Mobley (Department of Microbiology and Immunology, University of Michigan Medical School) for providing the Proteus mirabilis strain HI4320.

Funding This study was funded by the National Natural Science Foundation of China (No. 81200505 to Liang Peng).

\section{Compliance with ethical standards}

Conflict of interest The authors declare that they have no conflict of interest.

Ethical approval All applicable international, national and/or institutional guidelines for the care and use of animals were followed. All procedures performed in studies involving animals were in accordance with the ethical standards of the institution or practice at which the studies were conducted.

Open Access This article is distributed under the terms of the Creative Commons Attribution 4.0 International License (http://creativecommons.org/licenses/by/4.0/), which permits unrestricted use, distribution, and reproduction in any medium, provided you give appropriate credit to the original author(s) and the source, provide a link to the Creative Commons license, and indicate if changes were made. 


\section{References}

1. Jacobsen SM, Stickler DJ, Mobley HLT et al (2008) Complicated catheter-associated urinary tract infections due to Escherichia coli and Proteus mirabilis. Clin Microbiol Rev 21(1):26-59

2. Bouchillon SK, Badal RE, Hoban DJ et al (2013) Antimicrobial susceptibility of inpatient urinary tract isolates of gram-negative bacilli in the United States: results from the study for monitoring antimicrobial resistance trends (SMART) program: 2009-2011. Clin Ther 35(6):872-877

3. Swihartt KG, Welch RA (1990) Cytotoxic activity of the proteus hemolysin HpmA. Infect Immun 58(6):1861-1869

4. Nielubowicz GR, Mobley HL (2010) Host-pathogen interactions in urinary tract infection. Nat Rev Urol 7(8):430-441

5. Wang MC, Chien HF, Tsai YL et al (2014) The RNA chaperone $\mathrm{Hfq}$ is involved in stress tolerance and virulence in uropathogenic Proteus mirabilis. PLoS ONE 9(1):e85626

6. Peng L, Luo WY, Zhao T et al (2012) Polyphosphate kinase 1 is required for the pathogenesis process of meningitic Escherichia coli K1 (RS218). Future Microbiol 7(3):411-423

7. Ogawa N, Tzeng CM, Fraley $C D$ et al (2000) Inorganic polyphosphate in Vibrio cholerae: genetic, biochemical, and physiologic features. J Bacteriol 182(23):6687-6693

8. Rashid MH, Rumbaugh K, Passador L et al (2000) Polyphosphate kinase is essential for biofilm development, quorum sensing, and virulence of Pseudomonas aeruginosa. Proc Natl Acad Sci USA 97(17):9636-9641

9. Kim KS, Rao NN, Fraley CD et al (2002) Inorganic polyphosphate is essential for long-term survival and virulence factors in Shigella and Salmonella spp. Proc Natl Acad Sci USA 99(11):7675-7680

10. Pearson MM, Mobley HLT (2007) The type III secretion system of Proteus mirabilis HI4320 does not contribute to virulence in the mouse model of ascending urinary tract infection. J Med Microbiol 56:1277-1283

11. Silby MW, Nicoll JS, Levy SB (2009) Requirement of polyphosphate by Pseudomonas fluorescens Pf0-1 for competitive fitness and heat tolerance in laboratory media and sterile soil $\nabla$. Appl Environ Microbiol 75(12):3872-3881

12. Chi F, Wang Y, Gallaher TK et al (2009) Identification of IbeR as a stationary-phase regulator in meningitic Escherichia coli $\mathrm{K} 1$ that carries a loss-of-function mutation in rpoS. J Biomed Biotechnol 2009:520283

13. Allison C, Coleman N, Jones PL et al (1992) Ability of Proteus mirabilis to invade human urothelial cells is coupled to motility and swarming differentiation. Infect Immun 60(11):4740-4746

14. Paragas N, Kulkarni R, Werth M et al (2014) $\alpha$-Intercalated cells defend the urinary system from bacterial infection. J Clin Invest 124(7):2963-2976

15. Liaw SJ, Lai HC, Ho SW et al (2001) Characterisation of p-nitrophenylglycerol-resistant Proteus mirabilis super-swarming mutants. J Med Microbiol 50(12):1039-1048

16. Heikens E, Bonten MJ, Willems RJ (2007) Enterococcus surface protein Esp is important for biofilm formation of Enterococcus faecium E1162. J Bacteriol 22(189):8233-8240

17. Yang M, Liu W, Wang C et al (2006) Proteomic analysis of differential protein expression in early process of pancreatic regeneration in pancreatectomized rats. Acta Pharmacol Sin 27(5):568-578

18. Gur C, Coppenhagen-Glazer S, Rosenberg S et al (2013) Natural killer cell-mediated host defense against uropathogenic $E$. coli is counteracted by bacterial hemolysinA-dependent killing of NK cells. Cell Host Microbe 14:664-674

19. Abraham SN, Shin JS, Malaviya R (2001) Type 1 fimbriated Escherichia coli-mast cell interactions in cystitis. J Infect Dis 183(Suppl 1):S51-S55

20. Wood MW, Breitschwerdt EB, Gookin JL (2011) Autocrine effects of interleukin- 6 mediate acute-phase proinflammatory and tissue-reparative transcriptional responses of canine bladder mucosa. Infect Immun 79(2):708-715

21. Liaw SJ, Lai HC, Wang WB (2004) Modulation of swarming and virulence by fatty acids through the RsbA protein in Proteus mirabilis. Infect Immun 72(12):6836-6845

22. Jacobsen SM, Shirtliff ME (2011) Proteus mirabilis biofilms and catheter-associated urinary tract infections. Virulence 2(5):460-465

23. Bahrani FK, Massad G, Lockatell CV et al (1994) Construction of an MR/P fimbrial mutant of Proteus mirabilis: role in virulence in a mouse model of ascending urinary tract infection. Infect Immun 62(8):3363-3371

24. Arora SK, Ritchings BW, Almira EC et al (1998) The Pseudomonas aeruginosa flagellar cap protein, FliD, is responsible for mucin adhesion. Infect Immun 66(3):1000-1007

25. Mobley HLT, Belas R, Lockatell V et al (1996) Construction of a flagellum-negative mutant of Proteus mirabilis: effect on internalization by human renal epithelial cells and virulence in a mouse model of ascending urinary tract infection. Infect Immun 64(12):5332-5340

26. Nachin L, Nannmark U, Nyström T (2005) Differential roles of the universal stress proteins of Escherichia coli in oxidative stress resistance, adhesion, and motility. J Bacteriol 187(18):6265-6272

27. Santoro MG (2000) Heat shock factors and the control of the stress response. Biochem Pharmacol 59:55-63

28. Kornberg A, Kumble AD (1995) Inorganic polyphosphate in mammalian cells and tissues. J Biol Chem 270(11):5818-5822

29. Kulaev IS, Vagabov VM (1983) Polyphosphate metabolism in micro-organisms. Adv Microb Physiol 24:83-171

30. Brown MRW, Kornberg A (2008) The long and short of it: polyphosphate, PPK and bacterial survival. Trends Biochem Sci 33(6):284-290

31. Armbruster CE, Mobley HLT (2012) Merging mythology and morphology: the multifaceted lifestyle of Proteus mirabilis. Nat Rev Microbiol 10(11):743-754

32. Jansen AM, Lockatell V, Johnson DE et al (2004) Mannoseresistant Proteus-like fimbriae are produced by most Proteus mirabilis strains infecting the urinary tract, dictate the in vivo localization of bacteria, and contribute to biofilm formation. Infect Immun 72(12):7294-7305

33. Alamuri P, Lower M, Hiss JA et al (2010) Adhesion, invasion, and agglutination mediated by two trimeric autotransporters in the human uropathogen Proteus mirabilis. Infect Immun 78(11):4882-4894

34. Rocha SP, Elias WP, Cianciarullo AM et al (2007) Aggregative adherence of uropathogenic Proteus mirabilis to cultured epithelial cells. FEMS Immunol Med Microbiol 51(2):319-326

35. Sabbuba N, Hughes G, Stickler DJ (2002) The migration of Proteus mirabilis and other urinary tract pathogens over Foley catheters. BJU Int 89(1):55-60 